\title{
Culture That Facilitates Change: A Mixed Methods Study of Hospitals Engaged in Reducing Cesarean Deliveries
}

Emily C. White VanGompel, MD, $M P H^{1,2}$

Susan L. Perez, $P b D^{3}$

Avisek Datta, MS ${ }^{2}$

Francesca R. Carlock, $M P H^{2}$

Valerie Cape

Elliott K. Main, $M D^{4}$

'Department of Family Medicine, University of Chicago, Pritzker School of Medicine, Chicago, Illinois

${ }^{2}$ NorthShore University HealthSystem Research Institute, Evanston, Illinois

${ }^{3}$ Department of Public Health, California State University, Sacramento, California

${ }^{4}$ Stanford University, California Maternal Quality Care Collaborative, Stanford, California

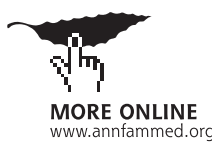

Conflicts of interest: authors report none

\section{CORRESPONDING AUTHOR}

Emily White VanGompel NorthShore University HealthSystem Research Institute 1001 University Pl

Evanston, IL 60201

ewhitevangompel@northshore.org

\begin{abstract}
PURPOSE Large-scale efforts to reduce cesarean deliveries have shown varied levels of impact; yet understanding factors that contribute to hospitals' success are lacking. We aimed to characterize unit culture differences at hospitals that successfully reduced their cesarean rates compared with those that did not.

METHODS A mixed methods study of California hospitals participating in a statewide initiative to reduce cesarean delivery. Participants included nurses, obstetricians, family physicians, midwives, and anesthesiologists practicing at participating hospitals. Hospitals' net change in nulliparous, term, singleton, and vertex cesarean delivery rates classified them as successful if they achieved either a minimum 5 percentage point reduction or rate of fewer than $24 \%$. The Labor Culture Survey was used to quantify differences in unit culture. Key informant interviews were used to explore quantitative findings and characterize additional cultural barriers and facilitators.
\end{abstract}

RESULTS Out of 55 hospitals, 37 ( $n=840$ clinicians) meeting inclusion criteria participated in the Labor Culture Survey. Physicians' individual attitudes differed by hospital success on 5 scales: best practices $(P=.003)$, fear $(P=.001)$, cesarean safety $(P=.014)$, physician oversight $(P<.001)$, and microculture $(P=.044)$ scales. Patient ability to make informed decisions showed poor agreement across all hospitals, but was higher at successful hospitals (38\% vs $29 \%, P=.01$ ). Important qualitative themes included: ease of access to shared resources on best practices, fear of bad outcomes, personal resistance to change, collaborative practice and effective communication, leadership engagement, and cultural flexibility.

CONCLUSIONS Successful hospitals' culture and context was measurably different from nonresponders. Leveraging these contextual factors may facilitate success.

Ann Fam Med 2021;19:249-257. https://doi.org/10.1370/afm.2675.

\section{INTRODUCTION}

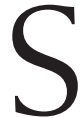
ince the Alliance for Maternal Safety released the Safe Reduction of Primary Cesarean/Support for Intended Vaginal Birth safety bundle in $2018,{ }^{1}$ statewide perinatal quality collaboratives have initiated large-scale efforts to reduce cesarean overuse. The Alliance for Maternal Safety bundle details the need to "Build a provider and maternity unit culture that values, promotes, and supports...vaginal birth," yet translating this into practice is challenging. In the United States, hospital-level cesarean delivery rates range from $6 \%$ to $69 \% .^{2}$ This variation cannot be adequately accounted for by differences in the health and risk profiles of childbearing women, ${ }^{3 \cdot 6}$ women's preferences, ${ }^{7,8}$ or hospital demographics. ${ }^{2,4,9}$

Changing the mix of clinicians within labor and delivery units may be a way to change unit culture and improve birth outcomes. ${ }^{10}$ Previous research has shown that clinicians who ascribe greater safety to cesarean birth and endorse greater fear of vaginal birth have increased individual clinician cesarean rates; with family physicians and midwives holding 
attitudes consistent with low cesarean utilizers. ${ }^{11}$ At the unit level, differences in labor culture (eg, attitudes of individuals and unit norms) are associated with nulliparous, term, singleton, vertex (NTSV) cesarean rates ${ }^{12}{ }_{i}$ however, the impact of labor and delivery unit culture on change efforts is not well characterized.

In 2015, the California Maternal Quality Care Collaborative (CMQCC) began the Supporting Vaginal Birth initiative to reduce cesarean delivery rates and range of variation in California. ${ }^{13,14}$ CMQCC focused on intervention characteristics and processes, including an aggressive mentoring structure, local champions, resource dissemination, and cross-pollination. ${ }^{13}$ Additionally, the state exerted substantial pressure on hospitals to reduce their cesarean rates to the Healthy People 2020 goal $(<24 \%)$, or face loss of revenue through exclusion from the health insurance exchange plans. ${ }^{15}$ Many hospitals saw significant reductions in cesarean rates after 18 months of participation; however, approximately $30 \%$ of hospitals remained unchanged and some saw an increase..$^{14}$ As similar initiatives move forward in other states, elucidating the mechanisms behind this differential success is essential.

In the course of creating the Supporting Vaginal Birth initiative, CMQCC focused heavily on intervention characteristics, such as those from the Institute for Healthcare Improvement collaborative model ${ }_{1}^{16}$ and specific processes (eg, mentoring, champions, and resource sharing). The outer setting in California included hospital public reporting and strong payer incentivization. ${ }^{13-15}$ With these domains already getting significant attention, this study aimed to elicit key characteristics of individuals and features of the inner setting of hospital labor and delivery units that impacted hospital success.

\section{METHODS}

\section{Sample}

Hospitals in the first 2 cohorts of the Supporting Vaginal Birth initiative $^{13,14}$ were eligible for inclusion. We excluded hospitals with baseline cesarean rates under the Healthy People 2020 goal $(<24 \%)$. We used annualized rates of NTSV cesarean delivery at each hospital before the start of the cesarean collaborative (2015) and after completion (2017) to calculate net change. Successful hospitals were defined as those with a postintervention rate of fewer than $24 \%$ cesarean deliveries; or, those that reduced their NTSV cesarean rate by at least 5 percentage points. The Stanford University Institutional Review Board approved the quantitative data collection on January 18, 2017, the full details of which have been previously published. ${ }^{12}$

\section{Implementation Science Framework}

The Consolidated Framework for Implementation Research (CFIR $)^{17}$ provides a systematic way to assess barriers and facilitators to change and can be adapted as needed to the specific intervention and setting (Figure 1). We measured these domains using the Labor Culture Survey (LCS), ${ }^{18}$ administered to participating hospitals in 2017, and key informant interviews with labor and delivery unit leaders. The LCS is a validated instrument that measures both individual attitudes and beliefs about birth practices, as well as individuals' perceptions of the cultural norms within the labor and delivery

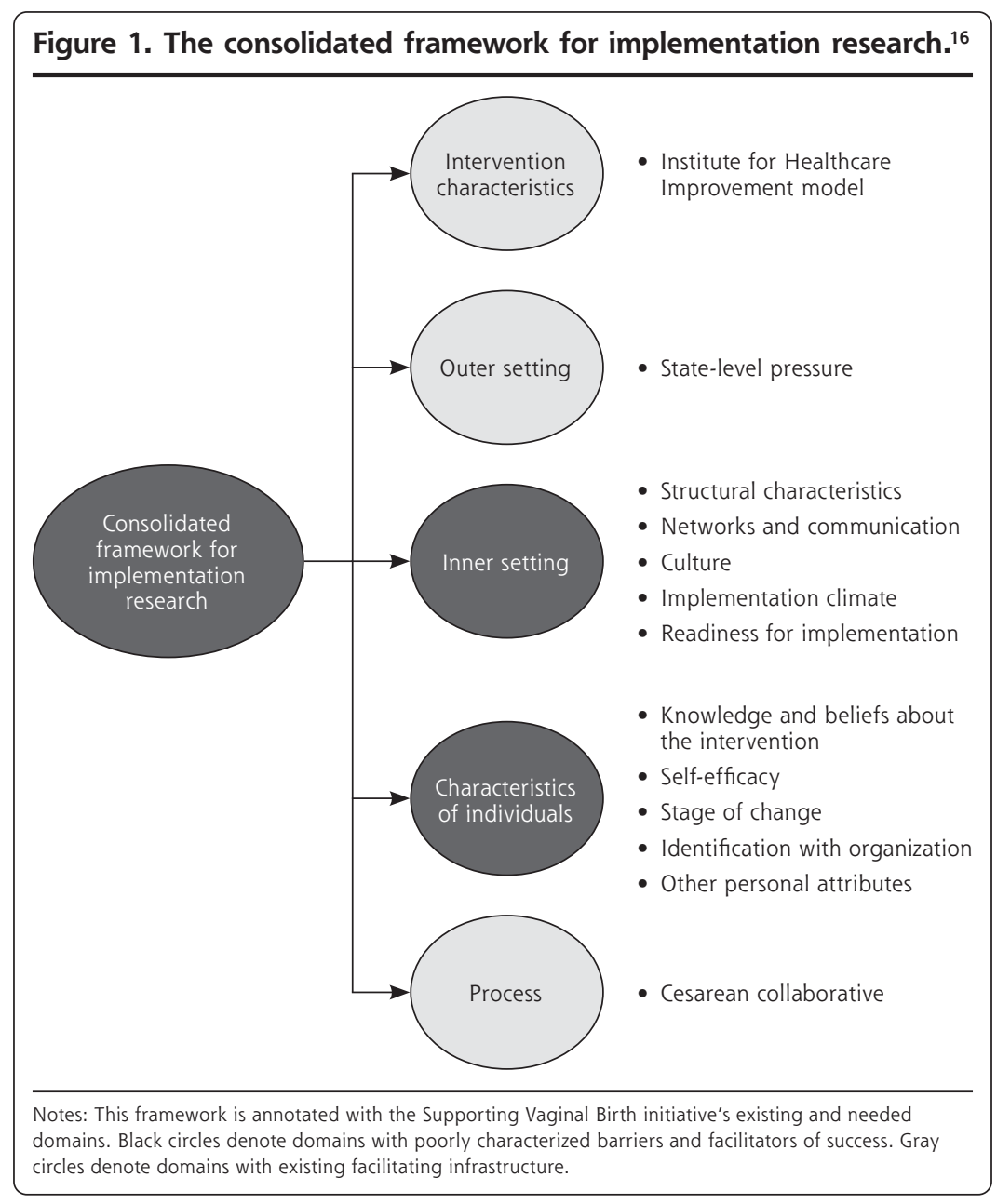


unit. Specific domains include agreement with best practices to reduce cesarean deliveries, physician oversight, maternal agency, personal fears of vaginal birth, overestimation of cesarean safety, and unit vaginal birth microculture (eg, perceived norms within the unit). ${ }^{18}$

\section{Statistical Analyses}

Characteristics of successful vs nonresponder hospitals were summarized at both the individual and hospital levels. Labor Culture Survey responses were compared for each group and stratified by maternity care role (nurses and physicians/midwives). Chi-square tests were used to test significance for categorical variables and Student's $t$-test for continuous variables. All analyses were performed using SAS software, Version 9.4 (SAS Institute Inc). ${ }^{19}$

\section{Key Informant Interviews}

The facilitator guide was developed in collaboration with clinicians who specialize in perinatal care and health services researchers. Using an iterative process to develop the facilitator guide, questions were developed based on the CFIR. Hospitals meeting inclusion criteria were stratified by successful reduction of cesarean deliveries, geographic location (Northern vs Southern California), and birth volume (large/ medium/small). From these strata, 8 hospitals were purposively sampled to gather a range of perspectives (Supplemental Table 1, https://www.AnnFamMed.org/ content/19/3/249/suppl/DC1/). Labor and delivery unit leaders at each hospital were identified by CMQCC staff, and additional key informants were identified via snowball sampling technique. All interviews were conducted and digitally audio recorded in Fall 2018 by a study team member (S.L.P.) trained in qualitative interviewing techniques. The recordings were then transcribed and deidentified. The California State University, Sacramento Institutional Review Board approved the qualitative data collection as exempt.

\section{Qualitative Analysis}

Transcripts were analyzed using inductive, grounded theory methodology. Themes were identified using the constant comparison method: (1) immersion in the transcripts (reading and rereading); $(2)$ the development of themes and codes; (3) coding the transcripts; and (4) reintegrating the codes into an explanatory narrative. Three members of the study team (E.W.V., S.L.P., F.R.C.) developed codes using the CFIR domains as a guiding framework. Coders had expertise in health services research (E.W.V., S.L.P., F.R.C.), clinical research and practice (E.W.V.), and maternity care (E.W.V., S.L.P.). Two members of the study team (E.W.V., S.L.P.) then hand-coded transcripts with continuous thematic cross-checking, and any discrepancies were brought to a third member of the study team for discussion until consensus was reached. In addition to the CFIR constructs, new themes were allowed to emerge.

\section{RESULTS}

\section{Quantitative: Labor Culture Survey (LCS)}

Of 66 hospitals in cohorts 1 and 2 of the cesarean collaborative, 11 were excluded due to already having a NTSV cesarean rate of less than $24 \%$. Changes in NTSV cesarean rates ranged from an increase of $4.7 \%$ to a maximal decrease of $16.7 \%$. Of the remaining 55 hospitals included in the study, 37 participated in the Labor Culture Survey. Participant roles included: labor and delivery nurses $(n=645)$, obstetricians $(n=143)$, certified nurse midwives $(\mathrm{n}=17)$, family medicine physicians $(n=18)$, anesthesiologists $(n=23)$, nurse educators $(n=17)$, and nurse managers $(n=35)$. Characteristics of participants and hospitals are presented in Supplemental Table 2, available at https://www.Ann FamMed.org/content/19/3/249/supp1/DC1/, stratified by hospital success. There were no significant hospitallevel demographic differences between the 2 groups. Physician survey participants at successful hospitals had been in practice for less time, on average, than those at nonresponder hospitals (mean 15.9 years vs 20.3 years, $P=.03$ ). Survey participants from successful hospitals also showed greater diversity in types of clinicians (significantly more respondents at successful hospitals were family physicians and midwives).

There were significant differences in LCS results by hospital success and physician/nurse strata (Supplemental Table 3, available at https://www.AnnFamMed. org/content/19/3/249/suppl/DC1/). Mean subscale scores differed for physicians on the best practices, fear, cesarean safety, physician oversight, and microculture scales. In contrast, only the microculture mean subscale score was significant for nurse participants at successful hospitals. Individual items with statistically significant differences by hospital success are presented below.

\section{LCS: Best Practices to Reduce Cesarean Subscale} Successful hospitals had significantly more physician agreement on providing more midwifery services (45\% vs $\left.24 \%{ }_{i} P=.017\right)$, implementing programs to support early labor at home $(76 \%$ vs $58 \% ; P=.022)$, providing more doula services ( $44 \%$ vs $17 \%$; $P=.002)$, and reducing the number of inductions of labor for nonmedical indications $(85 \%$ vs $63 \% ; P=.002)$. Nurses at all hospitals were universally more supportive of best practices than physicians. Nurse agreement with providing more 
Table 1. Labor Culture Survey ${ }^{18}$ Agreement With Best Practices to Reduce Cesarean Delivery

\begin{tabular}{|c|c|c|c|c|c|c|}
\hline \multirow[b]{2}{*}{ Best Practice, $\%$ in agreement } & \multicolumn{3}{|c|}{ Registered Nurses } & \multicolumn{3}{|c|}{ Medical Doctors } \\
\hline & $\begin{array}{c}\text { Nonresponder } \\
\text { Hospitals } \\
(\mathrm{n}=281)\end{array}$ & $\begin{array}{l}\text { Successful } \\
\text { Hospitals } \\
(n=378)\end{array}$ & $P$ Value & $\begin{array}{c}\text { Nonresponder } \\
\text { Hospitals } \\
(n=41)\end{array}$ & $\begin{array}{l}\text { Successful } \\
\text { Hospitals } \\
(n=130)\end{array}$ & $P$ Value \\
\hline Providing more midwifery service & 61.4 & 66.1 & .23 & 24.4 & 45.4 & $.017^{\mathrm{a}}$ \\
\hline $\begin{array}{l}\text { Implementing a program that supports } \\
\text { early labor at home }\end{array}$ & 87.2 & 89.3 & .44 & 57.5 & 76.2 & $.022^{\mathrm{a}}$ \\
\hline $\begin{array}{l}\text { Providing more direct (in room) nursing } \\
\text { time with laboring women }\end{array}$ & 75.2 & 81.9 & $.045^{\mathrm{a}}$ & 68.3 & 81.4 & .077 \\
\hline Providing more doula services & 40.2 & 47.9 & .06 & 17.1 & 43.9 & $.002^{\mathrm{a}}$ \\
\hline $\begin{array}{l}\text { Reducing the number of inductions of } \\
\text { labor for nonmedical indications }\end{array}$ & 96.4 & 94.6 & .30 & 63.4 & 85.4 & $.002^{\mathrm{a}}$ \\
\hline
\end{tabular}

direct (in room) nursing time with laboring women was the only item significantly different at successful hospitals ( $82 \%$ vs $75 \% ; P=.045$ ) (Table 1 ). Mean scores on LCS Best Practices scale from registered nurses was 4.08 (scale $1-5 ; P=.98$ ) for all hospitals, while medical doctors at successful hospitals rated agreement with this scale significantly higher than nonresponder hospitals (3.72 vs 3.32; $P=.003)$.

\section{LCS: Microculture Subscale}

Nurses at successful hospitals were more likely to endorse that the culture of their unit supports vaginal birth $(70 \%$ vs $59 \% ; P=.007)$, and less likely to state that there are too many cesareans performed on their unit $(46 \%$ vs $63 \% ; P<.001)$. Among all participants at successful hospitals, there was greater agreement that their patients have sufficient knowledge to make informed decisions; though overall agreement for both groups was low $(38 \%$ vs $29 \% ; P=.01)$, that doulas are welcomed onto the team $(54 \%$ vs $46 \% ; P=.03)$, and less agreement that clinician workflow considerations affect labor management decisions $(55 \%$ vs $63 \% ; P=.02)$.

\section{LCS: Physician Oversight Subscale}

Physicians at successful hospitals were significantly more likely to endorse: pre-cesarean-birth peer review of all elective cesareans, internal sharing of clinician cesarean rates, and departmental peer review of all cesarean births not meeting American College of Obstetricians and Gynecologists (ACOG)/Society for Maternal Fetal Medicine (SMFM) guidelines (mean scale score 3.5 vs $3.0 ; P<.001)$.

\section{LCS: Fear and Overestimation of Cesarean Safety Subscales}

Fear of vaginal birth and overestimation of cesarean safety was different for physicians at successful hospitals compared with physicians at nonresponder hospitals, but was not different for nurses. Significantly less physicians at successful hospitals agreed with the item, "If my partner or I were pregnant with an apparently normal pregnancy, I would prefer an elective cesarean birth instead of a vaginal birth" (4.6\% vs $14.6 \% ; P=.04)$. On the overall cesarean safety scale, physicians at successful hospitals were much less likely to agree that cesarean birth was safer for the baby and as safe for the mother (mean scale score 2.1 vs $2.5 ; P=.01$ ).

\section{Qualitative: Key Informant Interviews}

A total of 12 individuals representing 8 hospitals were interviewed. Key informants included 5 physicians and 7 registered nurses. All key informants held a leadership role within their hospital unit. Codes and definitions were developed using the CFIR framework to guide understanding of facilitators and barriers to change. Table 2 presents the most salient themes that were echoed across several CFIR constructs.

\section{Theme 1: Ease of Access to Shared Resources on Best Practices}

For the clinicians that participated in the interviews, shared access to the same information and knowledge across the entire unit was key to how units leveraged best practices in their day-to-day communications and decision making. In these scenarios, nurses felt confident confronting physicians because everyone had a shared understanding of "how things are done in the unit" (Table 2).

\section{Theme 2: Fear and Resistance to Change}

Key informants attributed fear and resistance to changing structural characteristics, such as the social architecture (eg, professional hierarchies, years practicing, staff turnover) and lack of compatibility with individuals' norms, values, and perceived risks 
and needs. Nurses and physicians each identified discipline-specific barriers to feeling comfortable with change. Nurses pointed to underlying fears about implementing new practices, such as allowing laboring patients to labor longer. Physicians tended to attribute their resistance to change due to a fear of malpractice litigation and bad outcomes. All key informants tended to categorize either resistance or openness to change through the lens of years in practice or age. Clinicians who had been in practice longer were perceived as having difficulty changing and adopting new practices (Table 2).

Table 2. CFIR Inner Setting Constructs, Contextualized Definitions, and Illustrative Quotes

\begin{tabular}{|c|c|c|c|}
\hline \multirow[b]{2}{*}{ Construct } & \multirow[b]{2}{*}{$\begin{array}{l}\text { Contextualized } \\
\text { Definition }\end{array}$} & \multicolumn{2}{|c|}{ Example Quotes From Focus Groups } \\
\hline & & Facilitators of Change & Barriers to Change \\
\hline \multirow[t]{5}{*}{$\begin{array}{l}\text { Structural } \\
\text { character- } \\
\text { istics }\end{array}$} & $\begin{array}{l}\text { Existing clinicians - } \\
\text { generational dif- } \\
\text { ferences in com- } \\
\text { munication and } \\
\text { teamwork styles }\end{array}$ & $\begin{array}{l}\text { "In general, everyone does have the desire to get } \\
\text { along and some of the older generation doctors } \\
\text { still live in the world of they're the boss and 'don't } \\
\text { tell me what to do.' But the majority of the physi- } \\
\text { cians...do appreciate the collaboration and have } \\
\text { that understanding that there's multiple checkpoints } \\
\text { along a patient's care path, and that anyone can } \\
\text { catch those." }\end{array}$ & \multirow[t]{2}{*}{$\begin{array}{l}\text { "Some of the older doctors that were kind of } \\
\text { set in their ways, we still have two of them } \\
\text { that just will not change no matter what we } \\
\text { do. We're just waiting for them to retire... } \\
\text { because it's hard to change a culture when } \\
\text { you have somebody who's been doing } \\
\text { something for like } 25 \text { years and refuses to } \\
\text { change, if they have a large portion of the } \\
\text { deliveries." }\end{array}$} \\
\hline & & $\begin{array}{l}\text { "A lot of these new physicians coming in listen to the } \\
\text { nurses now. They have a better relationship. They } \\
\text { know that the nurses are the ones at the bedside... } \\
\text { it's not so much, 'I'm the doctor. You're going to } \\
\text { do everything that I'm telling you to do.' There is a } \\
\text { different culture with physicians coming out of med } \\
\text { school now." }\end{array}$ & \\
\hline & $\begin{array}{l}\text { Size of the organi- } \\
\text { zation or hospital } \\
\text { unit and how } \\
\text { this impacts } \\
\text { perceived } \\
\text { organizational } \\
\text { characteristics } \\
\text { and impacts } \\
\text { outcomes }\end{array}$ & $\begin{array}{l}\text { "With the doctors too...we know each other very well, } \\
\text { especially because we have such a small number of } \\
\text { physicians working here." }\end{array}$ & $\begin{array}{l}\text { "We have certain doctors ...their episiotomy } \\
\text { rate is so high that it drags [the quality met- } \\
\text { rics down] - it's a small hospital....They'll } \\
\text { do maybe } 20,30 \text { deliveries a month, but } \\
\text { they do episiotomies on half of them so that } \\
\text { bumps your epis rate. So individual prac- } \\
\text { tices like that, especially in a small hospital } \\
\text { that doesn't [have a large] deliver(y) [vol- } \\
\text { ume], has a huge impact on your numbers." }\end{array}$ \\
\hline & $\begin{array}{l}\text { The current pro- } \\
\text { vider mix of LED } \\
\text { providers }\end{array}$ & $\begin{array}{l}\text { "we're in a pretty good place... [because we have } \\
\text { been] adding in midwives as the first call for low risk } \\
\text { patients. And so the nurses...find that so helpful that } \\
\text { they've got a midwife to work alongside." }\end{array}$ & $\begin{array}{l}\text { Quantitative/LCS Insight: Increasing the pres- } \\
\text { ence of midwives on LED was seen as a } \\
\text { good way to reduce cesarean by only } 24 \% \text { of } \\
\text { physicians at non-responder hospitals versus } \\
45 \% \text { at successful hospitals. }\end{array}$ \\
\hline & $\begin{array}{l}\text { The existence } \\
\text { or lack of for- } \\
\text { malized com- } \\
\text { munication } \\
\text { processes and } \\
\text { hierarchies; and } \\
\text { the functional } \\
\text { role of informal } \\
\text { communication } \\
\text { processes }\end{array}$ & $\begin{array}{l}\text { "I would say when we were really doing [Formal Team } \\
\text { Training Program], one of the things was after every } \\
\text { single delivery, good, bad or otherwise, we did a } \\
\text { debrief. And one of the things I liked about that was } \\
\text { we didn't wait for bad outcomes to do debriefs." } \\
\text { "...It's often centered around some discrepancy in } \\
\text { management, where I want the nurse to do some- } \\
\text { thing and she says, 'I can't. That's not protocol or } \\
\text { that's not policy,'... instead of... discarding that... } \\
\text { [we] dive into why nurses continue to follow certain } \\
\text { policies...It's just a larger discussion." }\end{array}$ & $\begin{array}{l}\text { "It can be awkward. Oftentimes, if a nurse } \\
\text { is having trouble with a provider or with } \\
\text { another nursing staff member, they'll talk } \\
\text { to the charge nurse...The first thing I'll say } \\
\text { is, well have you talked to the person? So } \\
\text { sometimes it gets difficult because people } \\
\text { don't want to hold each other account- } \\
\text { able...or they feel it's not their job to do it. } \\
\text {...You can't always just escalate every prob- } \\
\text { lem to [Nurse Manager]." }\end{array}$ \\
\hline \multirow[t]{2}{*}{ Culture } & \multirow[t]{2}{*}{$\begin{array}{l}\text { Norms and values } \\
\text { of unit, sub- } \\
\text { cultures of nurses } \\
\text { and physicians } \\
\text { and professional } \\
\text { siloes; Cultural } \\
\text { flexibility }\end{array}$} & $\begin{array}{l}\text { "Well I would say we're a huge team, and we treat } \\
\text { each other like family, and that includes the physi- } \\
\text { cians too that work with us. As far as patients, I feel } \\
\text { like we try to provide holistic patient care, including } \\
\text { patients, their family members, friends." } \\
\text { "When we're making the assignment, we take differ- } \\
\text { ent things into consideration... if there's someone } \\
\text { who has a natural approach... well so and so's going } \\
\text { to be great for this patient because that's... how } \\
\text { she likes to practice... the nurse then feels rewarded } \\
\text { because they're having the type of experience... } \\
\text { that is in alignment with their beliefs as well." }\end{array}$ & $\begin{array}{l}\text { "One of the things we've been able to over- } \\
\text { come, the nurses' story "we're the patient } \\
\text { advocate," somehow pinning the physician } \\
\text { as not the patient advocate. I don't hear } \\
\text { that as much anymore. It's been better } \\
\text { recognized that all of us are patient advo- } \\
\text { cates, but the nurses are still on a } 12 \text {-hour } \\
\text { shift and they're going to check out in } 12 \\
\text { hours and many of us [physicians] will still } \\
\text { continue on for days with a patient, if that's } \\
\text { how long it takes." }\end{array}$ \\
\hline & & & continues \\
\hline
\end{tabular}


Table 2. CFIR Inner Setting Constructs, Contextualized Definitions, and Illustrative Quotes (continued)

\begin{tabular}{|c|c|c|c|}
\hline \multirow[b]{2}{*}{ Construct } & \multirow{2}{*}{$\begin{array}{l}\text { Contextualized } \\
\text { Definition }\end{array}$} & \multicolumn{2}{|c|}{ Example Quotes From Focus Groups } \\
\hline & & Facilitators of Change & Barriers to Change \\
\hline \multirow[t]{4}{*}{$\begin{array}{l}\text { Implementa- } \\
\text { tion climate }\end{array}$} & \multirow[t]{2}{*}{$\begin{array}{l}\text { Fear and resistance } \\
\text { to change }\end{array}$} & \multirow{2}{*}{$\begin{array}{l}\text { "Just making it more obvious that there are more peo- } \\
\text { ple reaching out and trying to address this problem } \\
\text { and it's not going to go away. To me, the bottom } \\
\text { line is the physicians. The physicians are the ones } \\
\text { who make the call to do the C-section, nobody else. } \\
\text { So it's bottom line, you've got to get the physicians } \\
\text { more on board with everything." }\end{array}$} & $\begin{array}{l}\text { "Liability is a major player when it comes to } \\
\text { physicians and NTSV rates. I think the physi- } \\
\text { cians are scared to take risks and not go to } \\
\text { C-section because they're worried about the } \\
\text { liability." }\end{array}$ \\
\hline & & & $\begin{array}{l}\text { "I think... fear of a bad outcome, fear of sit- } \\
\text { ting on a strip too long and fear of getting } \\
\text { sued. But even more so is fear of having } \\
\text { to tell the mom, 'Your baby has a lot of } \\
\text { problems because, you know, we waited too } \\
\text { long [to call for a cesarean]'." }\end{array}$ \\
\hline & $\begin{array}{l}\text { Organizational } \\
\text { incentives } \delta \\
\text { rewards }\end{array}$ & $\begin{array}{l}\text { "Evidence based process and allow you to do audits } \\
\text { and all staff [were] audited. Amazing opinions on } \\
\text { how do things better. Did all units and started work- } \\
\text { ing. Put up reward boards, celebration,..., personal } \\
\text { notes and acknowledgement in huddles. Now they } \\
\text { are working on communication. Next collaboration } \\
\text { and teamwork. Staffing last per their assessment." }\end{array}$ & $\begin{array}{l}\text { "And those individuals that lack some moti- } \\
\text { vation or lack the understanding of, the } \\
\text { importance of some of this stuff and work- } \\
\text { ing with them individually... If I were to talk } \\
\text { about something right now to help improve, } \\
\text { it would be recognizing people for doing a } \\
\text { great job and getting that out there." }\end{array}$ \\
\hline & Goals $\&$ feedback & $\begin{array}{l}\text { "A lot of it is during our meetings. We have separate } \\
\text { meetings regarding the C-section rate, and sometimes } \\
\text { we may outline certain problem physicians or certain } \\
\text { physicians who are a little bit more quick in making } \\
\text { decisions. So some of those physicians have to be } \\
\text { spoken to individually and to encourage them to do } \\
\text { what they can to be a little bit more conservative." }\end{array}$ & \\
\hline $\begin{array}{l}\text { Learning } \\
\text { climate }\end{array}$ & $\begin{array}{l}\text { Team members } \\
\text { feel safe, input } \\
\text { is/isn't valued }\end{array}$ & $\begin{array}{l}\text { "The nurses are very strong and they're solid in their } \\
\text { skills, their knowledge in Labor \& Delivery. And so } \\
\text { I think that gives them more confidence with the } \\
\text { physicians and with the providers. And at the same } \\
\text { time, the providers then trust them when they are } \\
\text { asking them for something or if they're needing } \\
\text { support on something, the doctors are receiving } \\
\text { that pretty well because of the trust that they have } \\
\text { with their knowledge." }\end{array}$ & $\begin{array}{l}\text { "Some of our charge nurses can be a little bit } \\
\text { hard on newer people... When someone's } \\
\text { more of a slow learner or a slower learning } \\
\text { curve, there's sometimes not much patience } \\
\text { for that. I think we could do better." }\end{array}$ \\
\hline $\begin{array}{l}\text { Leadership } \\
\text { engagement }\end{array}$ & $\begin{array}{l}\text { Leadership com- } \\
\text { mitment, } \\
\text { involvement, and } \\
\text { accountability }\end{array}$ & $\begin{array}{l}\text { "Well, I just think that working together for so many } \\
\text { years, building that trust. I know we have a - our } \\
\text { chief medical officer is not an obstetrician, but he's } \\
\text { doing everything he can to learn about obstetrics. } \\
\text { So he really drives that from the doctor's side of it. } \\
\text { He is really instilling in the doctors the importance } \\
\text { of collaborating as a team. Not that they needed it } \\
\text { too much, but he just really reinforces it." }\end{array}$ & $\begin{array}{l}\text { "With [Nurse Manager] being the director } \\
\text { when she's telling people to please do } \\
\text { something, it really is more likely to be } \\
\text { done than if I was to ask them to do some- } \\
\text { thing...[Nurse Manager] is stretched very } \\
\text { thin. She has a lot of responsibilities around } \\
\text { the hospital and I think maybe it wasn't } \\
\text { totally on her radar so much either, even } \\
\text { though we had talked about it. But then } \\
\text { when it came down to it, it wasn't. And with } \\
\text { [Physician] being our physician champion, } \\
\text { it wasn't on her radar so much either, even } \\
\text { though we had talked about it." }\end{array}$ \\
\hline $\begin{array}{l}\text { Readiness for } \\
\text { implemen- } \\
\text { tation }\end{array}$ & $\begin{array}{l}\text { Level of resources } \\
\text { dedicated to } \\
\text { implementation } \\
\text { and operations; } \\
\text { Ease of access to } \\
\text { shared resources }\end{array}$ & $\begin{array}{l}\text { "We did a lot of joint education, which was great. } \\
\text { We did some fetal monitoring education with the } \\
\text { providers and the nurses. We've been doing simula- } \\
\text { tions. That's been great with pulling the providers } \\
\text { in. We conducted a retreat, a unit retreat about a } \\
\text { year ago." }\end{array}$ & $\begin{array}{l}\text { "The physicians themselves too, we don't have } \\
\text { a laborist program, so the doctors aren't } \\
\text { necessarily...here in-house. So knowing } \\
\text { that these other providers have } 30 \text {-minute } \\
\text { response times, sometimes the doctors } \\
\text { will decide to do a C-section a little bit } \\
\text { sooner than maybe they would in another } \\
\text { department when they know that they have } \\
\text { everyone readily available...like a Category } \\
2 \text { strip they might wait a little bit longer at } \\
\text { another facility because they have resources } \\
\text { readily available, but because we don't have } \\
\text { those resources always readily available } \\
\text { sometimes the doctors will make the deci- } \\
\text { sion to do a C-section a little bit earlier than } \\
\text { they may have at a different facility." }\end{array}$ \\
\hline
\end{tabular}

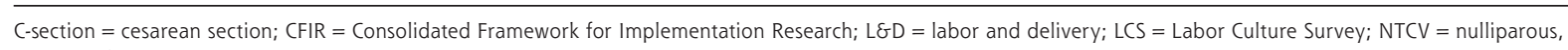
term, singleton, vertex. 
Theme 3: Collaborative Practice and Communication

Key informants identified effective communication as interprofessional receptivity to collaboration and standardized communication strategies. Similar to the concept of openness to change, this was described as changes in nurse-physician communication seen over time, with newer physicians demonstrating greater receptivity to a collaborative practice style and longer-practicing physicians preferring a hierarchical style (Table 2).

Some key informants noted that implementing standardized communication strategies successfully improved communication. The physician and nurse from the same successful hospital were consistent in their communication strategies whereas the physician and nurse from the nonresponder hospital were inconsistent in their communication strategies and alluded to communication avoidance (Table 3).

\section{Theme 4: Leadership Engagement}

Key informants from both types of hospitals cited the importance of leadership in their commitment to culture, involvement in understanding the day-to-day work tasks of the staff, and the ways in which the leadership holds themselves accountable to the staff. Strong leadership at all levels was perceived as playing an important role in developing and maintaining hospital unit culture (Table 2).

\section{Theme 5: The Role of Subcultures and Cultural Flexibility}

The ability to acknowledge, value, and utilize cultural diversity to improve patient care and professional work satisfaction was characterized as cultural flexibility by the study team. This was described by nurse key informants where nurses were assigned to patients with similar values and approaches to labor and birth (Table 2).

\section{DISCUSSION}

Our qualitative findings demonstrate that high levels of both effective communication, through formal and informal strategies, and leveling of hospital hierarchies were facilitators to the adoption of best practices known to reduce cesarean rates. Barriers to integrating best practices included the presence of rigid siloes by clinician discipline within the hospital unit, which were attributed by key informants to generational differences. Consistent with our qualitative findings, the
LCS identified that physicians' individual attitudes were measurably different, with physicians at successful hospitals less likely to prefer cesarean delivery for themselves or a loved one, and more likely to accept oversight. Nursing attitudes were universally more supportive of vaginal birth across all hospitals.

These findings are consistent with existing theories of culture change that characterize group affiliation, teamwork, and communication as more effective than hierarchical organizational culture to facilitate quality improvement ${ }_{r}^{20}$ and reinforce previous findings that attitudes, behaviors, and norms specific to supporting vaginal birth are traits of high-performing hospitals. ${ }^{12}$

\section{Implications for Practice}

Individual physician commitment and leadership, or lack thereof, was a critical factor in whether or not a hospital successfully lowered their cesarean rate. Lyndon recently used an organizational behavior theory of power differentials and hierarchy's impact on communication ${ }^{21}$ to illustrate the dysfunction that occurs with the historical roles of physicians holding greater power than nurses, and clinicians of all types holding power over patients. ${ }^{22}$ She posits that these power differentials lead to "silence and suppression of concerns" and the persistence of the "doctor-nurse game." ${ }^{13}$ Our findings suggest that this phenomenon is far from historical, as dysfunctional communication as a result of power differentials was described repeatedly by key informants. Prior research has highlighted a "leadership

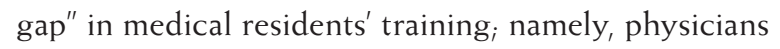
are unlikely to have been trained in team building and effective leadership, ${ }^{24}$ making formal trainings and tools even more imperative. Additionally, the striking differences in the personal attitudes of physicians (eg, a full $14.6 \%$ at unsuccessful hospitals would prefer cesarean for themselves or a loved one), show how deeply held beliefs may be in direct contradiction to evidencebased practice in individuals in charge of making clinical decisions. When viewed in conjunction with the power differentials described in qualitative interviews, 
this demonstrates a mechanism by which personal beliefs impact the outcomes of an entire unit.

Family medicine, a discipline that strongly identifies itself as valuing patient-centered care and shared decision making, ${ }^{25}$ may be in a unique position to contribute positively to this aspect of culture change on labor and delivery units. The finding that family physicians and midwives were disproportionately represented at hospitals that were successful suggests that the presence of greater clinician diversity may be a key structural component that facilitates change; either by promoting greater cultural flexibility, or as a source of unit leaders that hold attitudes more supportive of vaginal birth.

\section{Implications for Future Research}

An important, but disturbing, finding was that patient knowledge and ability to make informed decisions was rated poorly across all hospitals that participated in the collaborative; though successful hospitals had significantly more agreement that their patients were able to make informed decisions. A recent study of Alliance for Maternal Safety Cesarean Bundle implementation in Maryland noted that the readiness domain, which includes unit culture, patient and family engagement, and shared decision making had the least uptake and implementation across all hospitals after the first year of implementation. ${ }^{26}$ By demonstrating an association between these readiness components and hospital success, our study underscores the importance of measuring and developing interventions to directly address unit culture, patient engagement, and shared decision making in order to achieve successful cesarean delivery reduction.

This study had limitations, including its observational, cross-sectional study design. A longitudinal study design would provide stronger evidence that changing unit culture results in changes in practices. Within the context of participating in an initiative, social desirability bias could have affected LCS results; however, we would predict that this would drive results closer to nonsignificance, indicating our significant results are robust to this limitation. Our key informants were chosen from the leadership of each hospital, and may have different perceptions of leadership-initiated quality improvement than others at their hospitals thus, our qualitative results should be understood as a means to enrich the quantitative findings, rather than an exhaustive cataloging. Of note, this study was completed before widespread dissemination of the results of the A Randomized Trial of Induction Versus Expectant Management trial, ${ }_{1}^{27}$ which has caused notable controversy in labor units around the use of induction and its impact on cesarean delivery; one of the questions on the best practices subscale. Subsequent studies will need to examine attitudes and different approaches to incorporating this new evidence into practice and this question may need to be revised or eliminated.

\section{CONCLUSIONS}

Future work is needed to develop tools to facilitate organizational culture change as they relate to successful implementation of safety bundles, including leadership and team characteristics, communication strategies, and readiness to change metrics; which can then be studied to determine efficacy.

To read or post commentaries in response to this article, go to https://www. AnnFamMed.org/content/19/3/249/tab-e-letters.

Key words: cesarean section; health care quality; maternity hospital; organizational culture; patient care team

Submitted July 10, 2020; submitted, revised, October 26, 2020; accepted November 9, 2020.

Funding support: S.L.P., E.K.M., and V.C.'s effort was funded by a grant from the Yellow Chair Foundation. E.W.V., F.R.C., and A.D.'s effort was funded, in part, by the NorthShore Auxiliary Board. Neither sponsor had any role in the study design, data collection, analysis, or interpretation, writing of the report, or decision to submit the article for publication.

Previous presentation: These findings were presented at the 13th AcademyHealth 2019 Annual Research Meeting in Washington, DC, held on June 2-4, 2019, and as part of a keynote address given at the Michigan OBI kick-off event in November, 2019.

Acknowledgments: Christa Sakowski, employed by the California Maternal Quality Care Collaborative, participated in an advisory capacity during data collection and interpretation with internal funding. Leilani Jones, Catherine Xu, and Lavisha Singh, MS, employed at NorthShore University HealthSystem, assisted in preparation of the manuscript with internal funding.

- Supplemental materials: Available at https://www.AnnFamMed. org/content/19/3/249/suppl/DC1/.

\section{References}

1. Lagrew DC, Kane LL, Brennan R, et al. National Partnership for Maternal Safety: consensus bundle on safe reduction of primary cesarean births-supporting intended vaginal births. J Obstet Gynecol Neonatal Nurs. 2018;47(2):214-226.

2. Kozhimannil KB, Law MR, Virnig BA. Cesarean delivery rates vary tenfold among US hospitals; reducing variation may address quality and cost issues. Health Aff (Millwood). 2013;32(3):527-535.

3. Barber EL, Lundsberg LS, Belanger K, Pettker CM, Funai EF, Illuzzi $\mathrm{JL}$. Indications contributing to the increasing cesarean delivery rate. Obstet Gynecol. 2011;118(1):29-38.

4. Cáceres IA, Arcaya M, Declercq $E$, et al. Hospital differences in cesarean deliveries in Massachusetts (US) 2004-2006: the case against case-mix artifact. PLoS One. 2013;8(3):e57817.

5. Declercq E, Menacker F, Macdorman M. Maternal risk profiles and the primary cesarean rate in the United States, 1991-2002. Am J Public Health. 2006;96(5):867-872.

6. Rhodes JC, Schoendorf KC, Parker JD. Contribution of excess weight gain during pregnancy and macrosomia to the cesarean delivery rate, 1990-2000. Pediatrics. 2003;111(5 Pt 2):1181-1185. 
7. Declercq ER, Sakala C, Corry M, Applebaum S, Herrlich A. Listening to mothers III: pregnancy and birth; report of the 3rd national US Survey of Women's Childbearing Experiences. Childbirth Connection; 2013.

8. McCourt C, Weaver J, Statham H, Beake S, Gamble J, Creedy DK. Elective cesarean section and decision making: a critical review of the literature. Birth. 2007;34(1):65-79.

9. Baicker K, Buckles KS, Chandra A. Geographic variation in the appropriate use of cesarean delivery: do higher usage rates reflect medically innapropriate use of this procedure? Health Aff (Millwood). 2006;25(5):w355-w367.

10. Attanasio L, Kozhimannil KB. Relationship between hospital-level percentage of midwife-attended births and obstetric procedure utilization. J Midwifery Womens Health. 2018;63(1):14-22.

11. White VanGompel E, Main EK, Tancredi D, Melnikow J. Do provider birth attitudes influence cesarean delivery rate: a cross-sectional study. BMC Pregnancy Childbirth. 2018;18(1):184.

12. White VanGompel E, Perez S, Datta A, Wang C, Cape V, Main E. Cesarean overuse and the culture of care. Health Serv Res. 2019; 54(2):417-424.

13. Main EK, Chang SC, Cape V, Sakowski C, Smith H, Vasher J. Safety assessment of a large-scale improvement collaborative to reduce nulliparous cesarean delivery rates. Obstet Gynecol. 2019;133(4):613-623.

14. Smith H, Peterson N, Lagrew D, Main E. Toolkit to support vaginal birth and reduce primary cesareans. California Maternal Quality Care Collaborative. Updated Sep 20, 2017. Accessed Feb 11, 2020. https://www.cmqcc.org/VBirthToolkitResource

15. Covered California Board. Attachment 7 to Covered California Individual Contract: quality, network management, delivery system standards and improvement strategy. Accessed Feb 11, 2020. https://hbex.coveredca.com/insurance-companies/PDFs/Att-7-QHPUpdatefor-2018.pdf

16. Improving health care delivery: the "learning collaborative" approach. Commonwealth Fund. Published Jun 29, 2005; Accessed Apr 29, 2020. https://www.commonwealthfund.org/publications/publication/2005/jun/ improving-health-care-delivery-learning-collaborative-approach
17. Damschroder LJ, Aron DC, Keith RE, Kirsh SR, Alexander JA, Lowery $J C$. Fostering implementation of health services research findings into practice: a consolidated framework for advancing implementation science. Implement Sci. 2009:4:50.

18. White VanGompel E, Perez S, Wang C, Datta A, Cape V, Main E. Measuring labor and delivery unit culture and clinicians' attitudes toward birth: revision and validation of the Labor Culture Survey. Birth. 2019;46(2):300-310.

19. SAS Software. Version 9.4. Cary, NC: SAS Institute Inc; 2013.

20. Shortell SM, O'Brien JL, Carman JM, Foster RW, Hughes EF, Boerstler $\mathrm{H}, \mathrm{O}^{\prime}$ Connor EJ. Assessing the impact of continuous quality improvement/total quality management: concept versus implementation. Health Serv Res. 1995;30(2):377-401.

21. Morrison EW, Rothman NB. Silence and the dynamics of power. In: Greenberg J, Edwards M., eds. Voice and Silence in Organizations. Emerald Publishing; 2009:111-134.

22. Lyndon A. Failure to rescue, communication, and safety culture. Clin Obstet Gynecol. 2019;62(3):507-517.

23. Stein LI. The doctor-nurse game. Arch Gen Psychiatry. 1967;16(6): 699-703.

24. Blumenthal DM, et al. Addressing the leadership gap in medicine: residents' need for systematic leadership development training. Acad Med. 2012;87(4): 513-522.

25. Hudon C, Fortin M, Haggerty JL, Lambert M, Poitras M-E. Measuring patients' perceptions of patient-centered care: a systematic review of tools for family medicine. Ann Fam Med. 2011;9(2):155-164.

26. Callaghan-Koru JA, Creanga AA, DiPietro B, et al. Implementation of the safe reduction of primary cesarean births safety bundle during the first year of a statewide collaborative in Maryland. Obstet Gynecol. 2019;134(1):109-119.

27. Grobman WA, Rice MM, Reddy UM, Tita AT, Silver RM, Mallett G, Hill K, Thom EA, El-Sayed YY, Perez-Delboy A, Rouse DJ. Labor induction versus expectant management in low-risk nulliparous women. N Engl J Med. 2018 Aug 9;379(6):513-23. 